\title{
APPLICATION OF RESPONSE SURFACE MODELING FOR OPTIMIZATION AND DETERMINATION OF MALONDIALDIALDEHYDE BY VORTEX-ASSISTED DISPERSIVE LIQUID-LIQUID MICROEXTRACTION AND GC-FID
}

\author{
MAJID MIRMOGHADDAM ${ }^{a}$, MASSOUD KAYKHAII ${ }^{a}$, MOHAMMAD HASHEMI $^{b}$, \\ AHMAD JAMALI KEIKHA ${ }^{c}$, SAYYED HOSSEIN HASHEMI ${ }^{d, *}$ AND HOSSEIN YAHYAVI ${ }^{a}$ \\ ${ }^{a}$ Department of Chemistry, Faculty of Sciences, University of Sistan and Baluchestan, Zahedan, Iran. \\ ${ }^{b}$ Department of Biochemistry, School of Medicine, Zahedan University of Medical Sciences, Zahedan, Iran. \\ ${ }^{C}$ Department of Mechanical Engineering, Faculty of Marine Engineering, Chabahar Maritime University, Chabahar, Iran. \\ ${ }^{d}$ Department of Marine Chemistry, Faculty of Marine Science, Chabahar Maritime University, P.O. Box 98617-85553, Chabahar, \\ Iran. Tel: +98 (54) 33446413, Fax: 33446888.
}

\begin{abstract}
An analytical method based on vortex-assisted dispersive liquid-liquid microextraction and gas chromatography-flame ionization detection is presented for the extraction and determination of malondialdehyde (MDA) in blood plasma of human. Various parameters affecting the extraction efficiency such as type and volume of extraction and dispersive solvents, vortex and centrifuge times, volume, ionic strength and $\mathrm{pH}$ of the sample solution were evaluated using, one-variable-at-a-time and response surface methodology. In order to optimize the MDA extraction and determination, seven factors in five- levels were used for design of experiments (DOE). Under optimum extraction condition, this method showed linear range of calibration curve between $10-1150 \mu \mathrm{g} \mathrm{L}^{-1}$. The detection limit of the proposed method was found to be $0.8 \mu \mathrm{g} \mathrm{L}^{-1}$ with a relative standard deviation better than $5.5 \%(\mathrm{n}=10)$ for blood serum samples. Enrichment factor was calculated to be 175 fold and the total analysis time including microextraction was about $13 \mathrm{~min}$. The method was successfully applied for the analysis of MDA in blood plasma of human.
\end{abstract}

Keywords: Malondialdehyde, Vortex-assisted dispersive liquid-liquid microextraction, Response surface methodology, Human serum analysis, GC-FID.

\section{INTRODUCTION}

MDA is widely used as a biomarker for assessing oxidative stress in biomedical fields. Lipid peroxidation is a chain phenomenon resulting in the formation of various active compounds that result in cellular damage. Biomonitoring of malondialdehyde has been used in both biological and medical studies as a key biomarker for various disease patterns including hypertension, diabetes, atherosclerosis, neurodegenerative disorders, heart failure and cancer [1-4].

In the last decades a number of methods have been published for determination of the lipid peroxidation product, MDA, with improvements in analytical technologies and further development of HPLC [5], GC [6] and GC-MS [7]. However, because of the trace amount of MDA in body fluids, a derivatization step is universally necessary before sample injection, which is time consuming and also decreases the reproducibility. The level of MDA in biomedical samples is usually assessed by 2-thiobarbituric acid (TBA) assay. In the reaction between them, MDA forming an MDA-TBA ${ }_{2}$ adduct, a red complex. The level of MDA$\mathrm{TBA}_{2}$ adduct can be determined either by spectrofluorimeter or by spectrophotometer [8]. However, the method has been criticized for low selectivity and sensitivity since several MDA-unrelated species from biomedical samples can react with TBA. High performance capillary electrophoresis does not utilize derivatization, but it is too expensive for routine use of bioanalytical laboratories [9]. Utilizing extraction before chromatographic analysis can overcome these problems because it can pre-concentrate the analyte and furthermore, eliminate the interfering elements at the same time [10-12]. Meanwhile, no derivatization step will be necessary. Classical liquid-liquid extraction (LLE) is the most universally used separation technique, but it is labor, time consuming and requires high purity organic solvents which their disposal after usage brings a major threat to the environment $[13,14]$. Therefore researchers tried to extract MDA from serum media using extraction methods which consume less solvents such as solid phase extraction $[15,16]$ and solid phase microextraction $[17,18]$. However, these methods are complicated, expensive and time consuming [19-21]. Recently, one kind of extraction based on miniaturized conventional LLE is introduced, in which, the solvent to aqueous phase ratio is greatly reduced, leading to the development of solvent microextraction methodologies.

As a novel mode of solvent microextraction, dispersive liquid-liquid microextraction (DLLME) has been distinguished as a very popular preparation technique due to its simplicity of operation, time-saving, high enrichment factor and low cost [22-25]. In the prior studies, various techniques were employed for assisting dispersion in DLLME.
Manual shaking was a convenient and traditional procedure, but usually time consuming and non-efficient. Ultrasound assisted emulsification microextraction and microwave assisted emulsification microextraction were distinguished as two efficient and rapid methods [26]. However, these methods are consuming more energy and might cause analyte decomposition with more matrix interference. In 2010, Yiantzi et al. reported vortex assisted DLLME (VADLLME), a milder emulsification procedure compared with ultrasonic and microwave assisted DLLME, in which the extraction solvent was dispersed into aqueous samples by vortex mixing [27].

In this paper, a simple and rapid method using VADLLME followed by GC was applied for the determination of MDA in blood serum. Several parameters affecting microextraction have been optimized using including one-variable-ata-time and response surface methodology techniques, and the optimized method was successfully applied to serum samples analysis.

\section{EXPERIMENTAL}

\section{Reagents and materials}

All organic solvents and $\mathrm{NaCl}$ salt were of analytical grade and were purchased from Merck KGaA (Germany) and used as received. Milli- ${ }^{\circledR}$ water (18.3 M $\Omega$ $\mathrm{cm}^{-1}$ ) was used throughout the experiment after filtering through $0.22 \mathrm{~mm}$ Nylon membrane. 1,1,3,3-tetraethoxypropane (TEP) (99\%) as precursor of malondialdehyde preparation was also purchased from Merck KGaA (Germany). 1,1,3,3-tetramethoxypropane (TMP) was obtained from Sigma-Aldrich (St. Louis, MO, USA) and used as internal standard.

TEP was used to prepare a MDA stock solution. A volume of $10 \mu \mathrm{L}$ of TEP was accurately diluted to $10 \mathrm{~mL}$ with $0.1 \mathrm{~N} \mathrm{HCl}$ in a screw-capped test tube and incubated in boiling water bath for $15 \mathrm{~min}$ and then rapidly cooled with tap water. A working solution of MDA was prepared by pipetting $1 \mathrm{~mL}$ of this solution into a $100 \mathrm{~mL}$ volumetric flask and diluted to volume with ultrapure water. This solution contains $1 \mathrm{mg}$ of MDA per litter which is stable for few days at $4{ }^{\circ} \mathrm{C}$.

\section{Apparatus}

A Varian 450-GC gas chromatograph (Varian Inc., USA) equipped with a flame ionization detector was used for all analyses. The GC was fitted with a Varian capillary column $(30 \mathrm{~m} \times 0.32 \mathrm{~mm}$, film thickness $0.25 \mu \mathrm{m})$. The gas chromatography conditions were as follows: (1) the injector port was operated in split mode with a split ratio of 50:1 and it was kept at $200{ }^{\circ} \mathrm{C}$; (2) the FID temperature was $250^{\circ} \mathrm{C}$; (3) the initial oven temperature was $60^{\circ} \mathrm{C}$ for $1 \mathrm{~min}$, and increased to $140{ }^{\circ} \mathrm{C}$ at $20^{\circ} \mathrm{C} \mathrm{min}^{-1}$ then raised to $180{ }^{\circ} \mathrm{C}$ at $40{ }^{\circ} \mathrm{C} \mathrm{min}{ }^{-1}$, and 
remained for $1 \mathrm{~min}$ at this final temperature; (4) usage of high-purity nitrogen as a carrier gas $\left(1.8 \mathrm{~mL} \mathrm{~min}^{-1}\right)$. Hydrogen and air were used as detector gases at 30 and $300 \mathrm{~mL} \mathrm{~min}^{-1}$, respectively. A vortex mixer $(50 \mathrm{~Hz})$ from Labnet International, INC (USA) was used. Also for this work a Universal $32 \mathrm{R}$, Hettich Zentrifugen (Germany) centrifuge was employed. A Denver (Germany) model $\mathrm{UB}-10 \mathrm{pH}$ meter was used for $\mathrm{pH}$ measurements.

\section{VADLLME procedure}

$6 \mathrm{~mL}$ of the aqueous standard solution $\left(1 \mathrm{mg} \mathrm{L}^{-1}\right)$ or sample solution is transferred into a $10-\mathrm{mL}$ glass extraction vessel. A mixture of $450 \mu \mathrm{L}$ acetic acid as dispersive solvent with $150 \mu \mathrm{L}$ benzyl alcohol as extracting solvent is transferred into the vessel. The mixture was then vigorously shaken on vortex agitator for $1 \mathrm{~min}$ at max speed rate, a cloudy solution is obtained. Then, the mixture is centrifuged for $4 \mathrm{~min}$ at $2000 \mathrm{rpm}$. As a result of centrifugation, benzyl alcohol droplets were precipitated at the bottom of the centrifuge tube. Deposited phase was transferred to a micro-tube by a conventional sampler, from which, $0.9 \mu \mathrm{L}$ was mixed with $0.1 \mu \mathrm{L}$ of TMP (as internal standard) inside a GC microsyringe and injected into the GC. The microsyringe was cleaned with methanol three times before next injection to avoid formation of air bubbles and the carryover of compounds between extractions. In all cases, the analytical signal was recorded as the area ratio of the analyte peak to the internal standard peak. Calibration was performed using aqueous calibration solutions subjected to the same VADLLME procedure described above.

\section{RESULTS AND DISCUSSION}

\section{Optimization of VADLLME}

With the aim of achieving the best efficiency of the proposed method, different factors affecting extraction efficiency were investigated, including the type and volume of the extraction and dispersive solvents, vortex and centrifugation times, and volume, ionic strength and $\mathrm{pH}$ of the sample solution. A uni-variate approach was employed to optimize influential factors in order to simplify the optimization procedure. A series of experiments were designed for this purpose as discussed below.

\section{Type of the extraction solvent}

The selection of an appropriate extraction is a critical point for all microextraction processes. While the extraction solvent needs to be polar enough to have a large equilibrium distribution constant for MDA, it should have low solubility in aqueous, good extraction capability of the compound, low volatility and good chromatographic behavior. Based on these facts, six solvents including methyl isobutyl ketone, o- xylene, $\mathrm{n}$ - pentanol, $\mathrm{n}$-octanol, $\mathrm{n}$ - heptanol and benzyl alcohol were selected. The results are shown in Figure 1. The best extraction efficiency was achieved when benzyl alcohol was utilized as an extraction solvent. This solvent is suitable because benzyl alcohol is a polar, protic solvent with relatively high dielectric constant which can easily elute highly polar MDA. Thus, in the present study this solvent was used for all extractions.

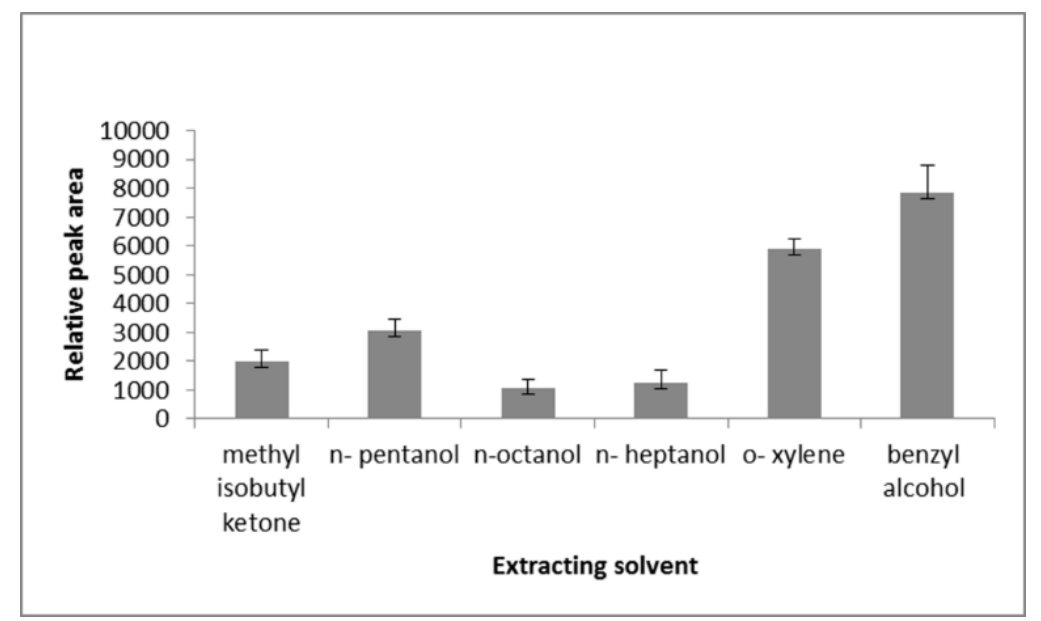

Figure 1. Effect of dispersive solvent on the extraction efficiency. Conditions: extraction solvent volume, $150 \mu \mathrm{L}$; dispersive solvent, acetic acid; dispersive solvent volume, $450 \mu \mathrm{L}$; vortex time, $60 \mathrm{~s}$; centrifuge time, $4 \mathrm{~min}$; sample volume, $4 \mathrm{~mL} ; \mathrm{pH}, 3$.

\section{Type of the dispersive solvent}

Methanol, ethanol, acetone, acetonitrile, and acetic acid were selected and examined as dispersive solvent. Also, extraction without the dispersive solvent was evaluated. From the five dispersive solvents tested, the acetic acid showed the best chromatographic behavior; also the highest efficiency was achieved with this solvent. Therefore, subsequent experiments were accomplished by using it. In vortex assisted DLLME, micro volumes of a low-density organic solvent are dispersed into an aqueous sample using vortex mixing, a mild emulsification procedure. The well micro droplets formed ensure fast partitioning rates, i.e. short equilibration times, due to the shorter diffusion distance and larger specific surface area.
Response surface methodology for optimization of the extraction of MDA

Response surface methodology (RSM) is an affordable and reliable technique to optimizing certain processes. This method leads to a reduction of designed experiments to study the effect of operation factors. To study the parameters affecting the pre-concentration of MDA, the seven factors in five-levels were used for design of experiments (DOE) (Table 1). The input variables were benzyl alcohol volume (A) (50-200 $\mu \mathrm{L}$ ), acetic acid volume (B) (150-450), vortex time (C) (20- $100 \mathrm{~s})$, centrifugation time (D) (2- $10 \mathrm{~min})$, volume of sample solution (E) (3- $7 \mathrm{~mL})$, amounts of $\mathrm{NaCl}(\mathrm{F})\left(10-40 \mathrm{~g} \mathrm{~L}^{-1}\right)$ and $\mathrm{pH}(\mathrm{G})(2-6)$. The factor levels were coded as $-2(-\alpha$, low $),-1,0$ (central point) $,+1,+2(+\alpha$, high).

Table 1. Design- Expert parameters and experimental.

\begin{tabular}{|c|c|c|c|c|c|}
\hline Factors & \multicolumn{5}{|c|}{ Level } \\
\hline Dispersive solvent volume $(\mu \mathrm{L})$ & 150 & 250 & 350 & 450 & 550 \\
\hline Vortex time(s) & 20 & 40 & 60 & 80 & 100 \\
\hline Volume of sample solution (mL) & 3 & 4 & 5 & 6 & 7 \\
\hline Concentration of $\mathrm{NaCl}\left(\mathrm{g} \mathrm{L}^{-1}\right)$ & 0 & 10 & 20 & 30 & 40 \\
\hline $\mathrm{pH}$ & 2 & 3 & 4 & 5 & 6 \\
\hline
\end{tabular}


Table 2 indicates the analyses of the experimental results of the second- order polynomial model for the MDA yield. The behavior of the system is described using the following quadratic equation.

$\mathrm{Y}=\beta_{0}+\sum \beta_{\mathrm{i}} \mathrm{X}_{\mathrm{i}}+\sum \beta_{\mathrm{ii}} \mathrm{X}_{\mathrm{ii}}+\sum \beta_{\mathrm{ij}} \mathrm{X}_{\mathrm{i}} \mathrm{X}_{\mathrm{j}}+\mathrm{e}$
Where $\mathrm{Y}$ is the natural logarithm of predicted response ( $\mathrm{Y}=\mathrm{Ln}($ Response $)), \beta_{0}$ is the constant, $X_{1}, X_{2}, \ldots, X_{k}$ are the coded independent variables, $\beta_{\mathrm{i}}$ is the linear effect, $\beta_{\mathrm{ii}}$ is the quadratic effect, $\beta_{\mathrm{ij}}$ demonstrates the coefficient of the interaction factor, e is the random error or allows for description or uncertainties between predicted and determined value [28].

Table 2. Matrix for the experiments of Design-Expert.

\begin{tabular}{|c|c|c|c|c|c|c|c|c|c|}
\hline Number & $\begin{array}{c}\text { Factor 1 (A): } \\
\text { Extraction } \\
\text { solvent volume } \\
(\mu \mathrm{L})\end{array}$ & $\begin{array}{c}\text { Factor } 2(B): \\
\text { Dispersive } \\
\text { solvent } \\
\text { volume }(\mu \mathrm{L})\end{array}$ & $\begin{array}{c}\text { Factor } 3 \\
\text { (C): Vortex } \\
\text { time (s) }\end{array}$ & $\begin{array}{l}\text { Factor } 4(D): \\
\text { Centrifuge } \\
\text { time (min) }\end{array}$ & $\begin{array}{l}\text { Factor } 5(\mathrm{E}): \\
\text { Volume of } \\
\text { sample solution } \\
(\mathrm{mL})\end{array}$ & $\begin{array}{l}\text { Factor } 6(\mathrm{~F}): \\
\text { Concentration of } \\
\mathrm{NaCl}\left(\mathrm{g} \mathrm{L}^{-1}\right)\end{array}$ & $\begin{array}{l}\text { Factor } 7 \\
\text { (G): pH }\end{array}$ & $\begin{array}{l}\text { Response } \\
\text { (relative } \\
\text { peak area) }\end{array}$ & predicted \\
\hline 1 & 200 & 250 & 80 & 8 & 4 & 10 & 3 & 38.1 & 38.0772 \\
\hline 2 & 100 & 450 & 40 & 4 & 4 & 30 & 5 & 0.4 & 0.400488 \\
\hline 3 & 200 & 450 & 80 & 8 & 6 & 30 & 5 & 8.8 & 8.765089 \\
\hline 4 & 200 & 250 & 40 & 4 & 4 & 30 & 5 & 2.4 & 2.411551 \\
\hline 5 & 100 & 250 & 40 & 4 & 6 & 30 & 3 & 65.7 & 65.70344 \\
\hline 6 & 100 & 250 & 80 & 4 & 4 & 30 & 3 & 45.9 & 45.76249 \\
\hline 7 & 200 & 250 & 40 & 8 & 6 & 10 & 3 & 48.8 & 48.61024 \\
\hline 8 & 150 & 350 & 60 & 6 & 5 & 20 & 4 & 2.9 & 2.89312 \\
\hline 9 & 150 & 350 & 20 & 6 & 5 & 20 & 4 & 4.1 & 4.098048 \\
\hline 10 & 50 & 350 & 60 & 6 & 5 & 20 & 4 & 2.9 & 2.892918 \\
\hline 11 & 100 & 450 & 40 & 8 & 6 & 30 & 3 & 40.8 & 40.73553 \\
\hline 12 & 150 & 350 & 60 & 6 & 7 & 20 & 4 & 4.5 & 4.534434 \\
\hline 13 & 200 & 450 & 40 & 4 & 6 & 30 & 5 & 8.4 & 8.365468 \\
\hline 14 & 200 & 450 & 80 & 8 & 6 & 10 & 3 & 59.6 & 59.00009 \\
\hline 15 & 100 & 450 & 80 & 4 & 6 & 10 & 5 & 8.8 & 8.748922 \\
\hline 16 & 200 & 450 & 40 & 4 & 4 & 30 & 3 & 40.3 & 40.08068 \\
\hline 17 & 200 & 250 & 80 & 4 & 6 & 10 & 3 & 70.9 & 70.28432 \\
\hline 18 & 150 & 350 & 60 & 6 & 5 & 20 & 4 & 3.0 & 2.89312 \\
\hline 19 & 150 & 350 & 60 & 6 & 5 & 20 & 4 & 2.9 & 2.89312 \\
\hline 20 & 150 & 350 & 60 & 10 & 5 & 20 & 4 & 8.1 & 8.058268 \\
\hline 21 & 200 & 250 & 40 & 4 & 6 & 10 & 5 & 12.4 & 12.37713 \\
\hline 22 & 100 & 250 & 80 & 4 & 4 & 10 & 5 & 9.2 & 9.170646 \\
\hline 23 & 200 & 250 & 80 & 8 & 6 & 30 & 3 & 51.5 & 51.53698 \\
\hline 24 & 150 & 350 & 60 & 6 & 5 & 40 & 4 & 2.7 & 2.65607 \\
\hline 25 & 150 & 350 & 60 & 2 & 5 & 20 & 4 & 3.2 & 3.200531 \\
\hline 26 & 100 & 450 & 40 & 4 & 6 & 10 & 3 & 59.5 & 58.99041 \\
\hline 27 & 250 & 350 & 60 & 6 & 5 & 20 & 4 & 4.0 & 3.989818 \\
\hline 28 & 150 & 350 & 60 & 6 & 5 & 20 & 2 & 32.5 & 32.76319 \\
\hline 29 & 150 & 350 & 60 & 6 & 5 & 20 & 4 & 2.85 & 2.89312 \\
\hline 30 & 100 & 250 & 80 & 8 & 4 & 30 & 5 & 4.8 & 4.818307 \\
\hline 31 & 150 & 350 & 60 & 6 & 5 & 20 & 4 & 2.95 & 2.89312 \\
\hline 32 & 100 & 250 & 40 & 8 & 6 & 30 & 5 & 9.0 & 8.986247 \\
\hline 33 & 150 & 350 & 60 & 6 & 5 & 0 & 4 & 13.2 & 13.35143 \\
\hline 34 & 100 & 450 & 80 & 4 & 6 & 30 & 3 & 61.1 & 60.86098 \\
\hline 35 & 200 & 450 & 40 & 4 & 4 & 10 & 5 & 7.4 & 7.359508 \\
\hline 36 & 200 & 450 & 80 & 4 & 4 & 30 & 5 & 4.2 & 4.194015 \\
\hline 37 & 200 & 450 & 40 & 8 & 4 & 10 & 3 & 37.2 & 37.17129 \\
\hline 38 & 200 & 250 & 80 & 8 & 6 & 10 & 5 & 12.7 & 12.70623 \\
\hline 39 & 100 & 450 & 80 & 4 & 4 & 10 & 3 & 51.6 & 51.41452 \\
\hline 40 & 150 & 350 & 60 & 6 & 3 & 20 & 4 & 3.7 & 3.653607 \\
\hline 41 & 100 & 450 & 80 & 8 & 4 & 10 & 5 & 2.5 & 2.48668 \\
\hline 42 & 150 & 350 & 100 & 6 & 5 & 20 & 4 & 1.1 & 1.095043 \\
\hline 43 & 150 & 550 & 60 & 6 & 5 & 20 & 4 & 3.7 & 3.775524 \\
\hline 44 & 150 & 350 & 60 & 6 & 5 & 20 & 6 & 0.5 & 0.49346 \\
\hline 45 & 100 & 250 & 80 & 8 & 6 & 10 & 3 & 60.5 & 60.14196 \\
\hline 46 & 100 & 250 & 40 & 8 & 4 & 30 & 3 & 27 & 27.01786 \\
\hline 47 & 100 & 250 & 40 & 8 & 4 & 10 & 5 & 8.1 & 8.09104 \\
\hline 48 & 150 & 150 & 60 & 6 & 5 & 20 & 4 & 2.2 & 2.216949 \\
\hline 49 & 150 & 350 & 60 & 6 & 5 & 20 & 4 & 2.9 & 2.89312 \\
\hline 50 & 200 & 450 & 40 & 8 & 4 & 30 & 5 & 3.0 & 3.011632 \\
\hline
\end{tabular}

The most commonly selected technique in the RSM method is central composite design (CCD). Design Expert software was applied for RSM regression analysis and optimization of input parameters by observed response (relative peak area). The statistical testing of the model, which inclusive linear, quadratic and interaction coefficient, was carried out with ANOVA analysis by $F$-test to achieve the empirical correlation between input and output parameters.
To evaluate the goodness of fit of the model, each term of model was tested statistically which confirmed the significance of $F$-values by $\mathrm{p} \leq 0.05$. The values of $\mathrm{R}^{2}$, adjusted $\mathrm{R}^{2}$ and predicted $\mathrm{R}^{2}$, lack of fit and adequate precision of models were obtained to check the quality of the proposed polynomial. To visualize the input-output relationships, the response surface plot and contour plot were drawn. 
The quadratic model in terms of actual value variables is indicated in equation (2).

$\mathrm{Y}=97.38644-0.34173 \times \mathrm{A}-0.41575 \mathrm{~B}-2.92176 \mathrm{C}+6.41213 \mathrm{D}+3.11689$ $\mathrm{E}+0.36924 \mathrm{~F}+17.64255 \times \mathrm{G}+1.10425 \times 10^{-3} \times \mathrm{A} \times \mathrm{B}+0.022379 \times \mathrm{A} \times \mathrm{C}$ $-0.16075 \mathrm{~A} \times \mathrm{D}-9.71520 \times 10^{-3} \times \mathrm{A} \times \mathrm{E}-7.57030 \times 10^{-4} \times \mathrm{F}+0.010507 \times \mathrm{B}$ $\times \mathrm{C}-0.051758 \times \mathrm{B} \times \mathrm{D}+0.020778 \times \mathrm{B} \times \mathrm{E}+2.39083 \times 10^{-3} \times \mathrm{B} \times \mathrm{F}-7.72269$ $\times 10^{-3} \times \mathrm{G}+0.042713 \times \mathrm{C} \times \mathrm{D}-0.13840 \times \mathrm{C} \times \mathrm{E}+7.78166 \times 10^{-3}-0.069701$ $\times \mathrm{C} \times \mathrm{G}+2.43061 \times \mathrm{D} \times \mathrm{E}+0.026222 \times \mathrm{D} \times \mathrm{F}-0.25383 \times \mathrm{D} \times \mathrm{G}-0.21088 \times$ $\mathrm{E} \times \mathrm{F}-2.93199 \times \mathrm{E} \times \mathrm{G}-0.14032 \times \mathrm{F} \times \mathrm{G}+1.6067 \times 10-5(\mathrm{~A})^{2}-1.94802 \times$ $10-4(\mathrm{C})^{2}+0.035167(\mathrm{D})^{2}+0.085343(\mathrm{E})^{2}+1.80475 \times 10^{-3}(\mathrm{~F})^{2}-0.82365(\mathrm{G})^{2}$ $-6.43265 \times 10^{-5} \times \mathrm{A} \times \mathrm{B} \times \mathrm{C}+4.70649 \times 10^{-4} \times \mathrm{A} \times \mathrm{B} \times \mathrm{D}-2.55848 \times 10^{-4} \times$ $\mathrm{B} \times \mathrm{C} \times \mathrm{E}+5.21769 \times 10^{-6} \times \mathrm{B} \times \mathrm{C} \times \mathrm{F}-6.49897 \times 10^{-4} \times \mathrm{B} \times \mathrm{D} \times \mathrm{E}-1.53885$ $\times 10^{-4} \mathrm{~B} \times \mathrm{D} \times \mathrm{F}-8.64585 \times 10^{-4} \times \mathrm{B} \times \mathrm{D} \times \mathrm{G}+4.76582 \times 10^{-3} \times \mathrm{B} \times \mathrm{E} \times \mathrm{G}+$ $0.015099 \times \mathrm{C} \times(\mathrm{G})^{2}$

Table 3. ANOVA analysis for multiple response function.

\begin{tabular}{|c|c|c|c|c|c|c|}
\hline Source & Sum of Squares & df & Mean Square & $F$ Value & p-value Prob $>$ F & $(\mathrm{PC} \%)^{\mathrm{a}}$ \\
\hline Model & 90.90467 & 42 & 2.164397 & 4282.818 & $<0.0001$ & - \\
\hline A-Extraction solvent volume & 0.051708 & 1 & 0.051708 & 102.3177 & $<0.0001$ & 0.047 \\
\hline B- dispersive solvent volume & 0.153722 & 1 & 0.153722 & 304.1786 & $<0.0001$ & 0.14 \\
\hline C-Vortex time & 0.865503 & 1 & 0.865503 & 1712.621 & $<0.0001$ & 0.79 \\
\hline D-Centrifuge time & 0.432948 & 1 & 0.432948 & 856.6985 & $<0.0001$ & 0.40 \\
\hline E-Volume of sample solution & 0.028058 & 1 & 0.028058 & 55.5203 & 0.0001 & 0.026 \\
\hline F-Concentration of $\mathrm{NaCl}$ & 1.851616 & 1 & 1.851616 & 3663.9 & $<0.0001$ & 1.69 \\
\hline G-pH & 10.55827 & 1 & 10.55827 & 20892.26 & $<0.0001$ & 9.67 \\
\hline $\mathrm{AB}$ & 0.738218 & 1 & 0.738218 & 1460.755 & $<0.0001$ & 0.67 \\
\hline $\mathrm{AC}$ & 0.053346 & 1 & 0.053346 & 105.5579 & $<0.0001$ & 0.049 \\
\hline $\mathrm{AD}$ & 0.387922 & 1 & 0.387922 & 767.6048 & $<0.0001$ & 0.35 \\
\hline $\mathrm{AE}$ & 0.566311 & 1 & 0.566311 & 1120.592 & $<0.0001$ & 0.52 \\
\hline $\mathrm{AF}$ & 0.278881 & 1 & 0.278881 & 551.8389 & $<0.0001$ & 0.25 \\
\hline $\mathrm{BC}$ & 1.273357 & 1 & 1.273357 & 2519.665 & $<0.0001$ & 1.16 \\
\hline $\mathrm{BD}$ & 5.627325 & 1 & 5.627325 & 11135.12 & $<0.0001$ & 5.15 \\
\hline $\mathrm{BE}$ & 6.693145 & 1 & 6.693145 & 13244.12 & $<0.0001$ & 6.13 \\
\hline $\mathrm{BF}$ & 6.254488 & 1 & 6.254488 & 12376.12 & $<0.0001$ & 5.73 \\
\hline BG & 3.241148 & 1 & 3.241148 & 6413.448 & $<0.0001$ & 2.97 \\
\hline $\mathrm{CD}$ & 5.758564 & 1 & 5.758564 & 11394.81 & $<0.0001$ & 5.27 \\
\hline $\mathrm{CE}$ & 8.135653 & 1 & 8.135653 & 16098.49 & $<0.0001$ & 7.45 \\
\hline $\mathrm{CF}$ & 6.336956 & 1 & 6.336956 & 12539.31 & $<0.0001$ & 5.80 \\
\hline $\mathrm{CG}$ & 2.791283 & 1 & 2.791283 & 5523.274 & $<0.0001$ & 2.55 \\
\hline $\mathrm{DE}$ & 7.103907 & 1 & 7.103907 & 14056.92 & $<0.0001$ & 6.50 \\
\hline DF & 0.969101 & 1 & 0.969101 & 1917.617 & $<0.0001$ & 0.89 \\
\hline DG & 3.019493 & 1 & 3.019493 & 5974.848 & $<0.0001$ & 2.76 \\
\hline $\mathrm{EF}$ & 6.996587 & 1 & 6.996587 & 13844.55 & $<0.0001$ & 6.41 \\
\hline EG & 5.680252 & 1 & 5.680252 & 11239.85 & $<0.0001$ & 5.2 \\
\hline FG & 5.32179 & 1 & 5.32179 & 10530.54 & $<0.0001$ & 4.87 \\
\hline $\mathrm{A}^{\wedge} 2$ & 0.041304 & 1 & 0.041304 & 81.73035 & $<0.0001$ & 0.038 \\
\hline $\mathrm{C}^{\wedge} 2$ & 0.155435 & 1 & 0.155435 & 307.568 & $<0.0001$ & 0.14 \\
\hline $\mathrm{D}^{\wedge} 2$ & 0.506565 & 1 & 0.506565 & 1002.37 & $<0.0001$ & 0.46 \\
\hline$E^{\wedge} 2$ & 0.186457 & 1 & 0.186457 & 368.9525 & $<0.0001$ & 0.17 \\
\hline$F^{\wedge} 2$ & 0.833828 & 1 & 0.833828 & 1649.944 & $<0.0001$ & 0.76 \\
\hline $\mathrm{G}^{\wedge} 2$ & 0.173411 & 1 & 0.173411 & 343.1386 & $<0.0001$ & 0.16 \\
\hline $\mathrm{ABC}$ & 7.173609 & 1 & 7.173609 & 14194.84 & $<0.0001$ & 6.57 \\
\hline ABD & 6.52802 & 1 & 6.52802 & 12917.37 & $<0.0001$ & 5.98 \\
\hline $\mathrm{BCE}$ & 0.510086 & 1 & 0.510086 & 1009.337 & $<0.0001$ & 0.48 \\
\hline BCF & 0.042987 & 1 & 0.042987 & 85.06027 & $<0.0001$ & 0.04 \\
\hline $\mathrm{BDE}$ & 0.067618 & 1 & 0.067618 & 133.7991 & $<0.0001$ & 0.062 \\
\hline $\mathrm{BDF}$ & 0.290729 & 1 & 0.290729 & 575.2831 & $<0.0001$ & 0.27 \\
\hline BDG & 0.11967 & 1 & 0.11967 & 236.7988 & $<0.0001$ & 0.11 \\
\hline BEG & 1.148444 & 1 & 1.148444 & 2272.492 & $<0.0001$ & 1.05 \\
\hline $\mathrm{CG}^{\wedge} 2$ & 0.337441 & 1 & 0.337441 & 667.7148 & $<0.0001$ & 0.31 \\
\hline Residual & 0.003538 & 7 & 0.000505 & & & \\
\hline Lack of Fit & 0.001982 & 2 & 0.000991 & 3.18449 & 0.1283 & \\
\hline Pure Error & 0.001556 & 5 & 0.000311 & & & \\
\hline
\end{tabular}

The obtained values for the critical points are as follows: benzyl alcohol volume $=100 \mu \mathrm{L}$, acetic acid volume $=251 \mu \mathrm{L}$, vortex time $=79.85 \mathrm{~s}$, centrifugation time $4.02 \mathrm{~min}$, volume of sample solution $=5.98 \mathrm{~mL}$, amounts of $\mathrm{NaCl}=10 \mathrm{~g} \mathrm{~L}^{-1}$ and $\mathrm{pH}=3.03$. percent contribution (PC \%) of each of the individual term in final model were computed (Table 3) [29].

$$
\% \mathrm{PC}=\left(\mathrm{SS} / \sum \mathrm{SS}\right) \times 100
$$

The results of the response surface model fitting in the form of analysis of variance (ANOVA) are showed in Table 3. The ANOVA results determine which the model was significant, as evident from the Fisher's $F$ test $\left(F_{\text {model }}=4282.818\right)$ by a very low probability value $\left(p_{\text {model }}=<0.0001\right)$.
Using the sum of squares (SS) values of the corresponding term (Eq. 3), the 
Design- Expert software generated two dimensional response surface plots indicated in Figure 2. With the correlation coefficient $\left(\mathrm{R}^{2}\right)$ the goodness of the model was checked. The adjusted $\mathrm{R}^{2}$ value of 0.999728 indicated which only $0.0272 \%$ of the total variation was not described using the model. Hence, the graph in Figure 3 shows a good correlation the value of between the experimental and predicted data of the response $\left(\mathrm{R}^{2}=0.999\right)$. The lack-of-fit determine the failure of the model to represent value in the experimental domain at point that is not included in the regression [29]. The not significant data of lack-of-fit $(>0.05)$ revealed which the quadratic model is statistically significant for the response.
$\mathbf{A}$

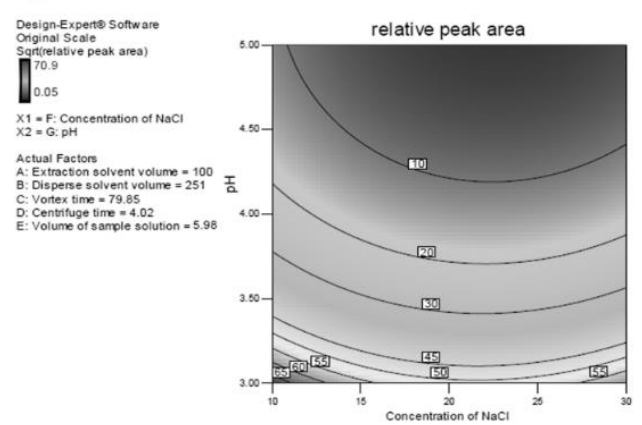

B

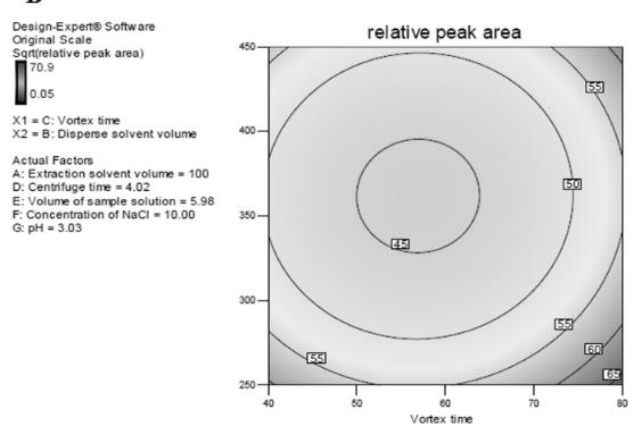

B

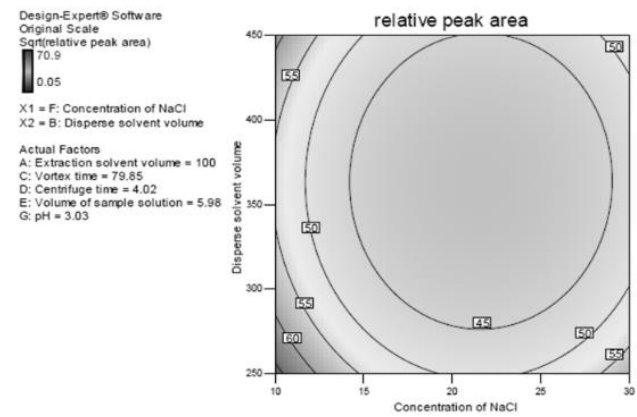

C

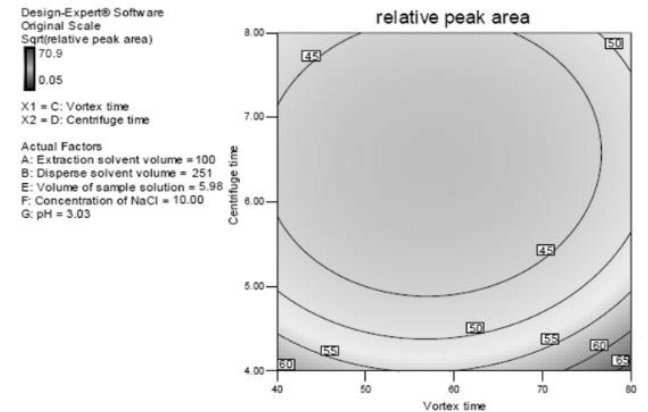

D

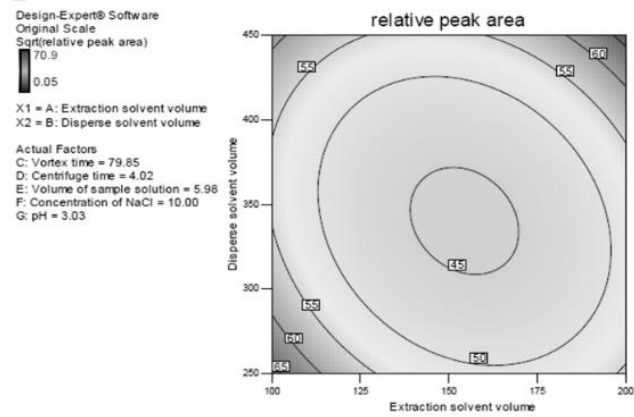

Figure 2. Response surface-2D/ contours showing the effect of independent variable on the relative peak area of MDA.

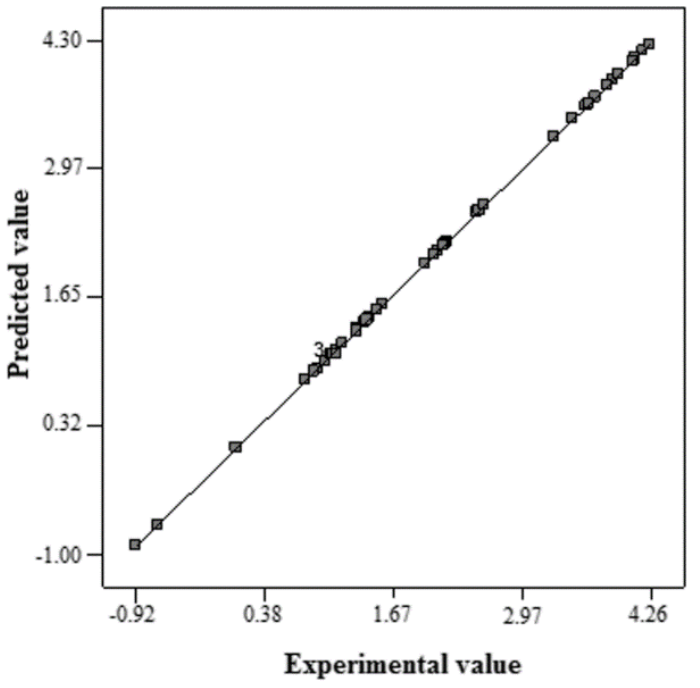

Figure 3. Correlation plots between predicted and experimental values. 


\section{Analytical performance for determination of MDA by VADLLME}

\section{Linear range, limit of detection and precision}

Under the optimized conditions, the linearity of the VADLLME method was examined by extracting the aqueous MDA samples. The calibration curve was linear for the concentrations ranging 10 to $1150 \mu \mathrm{g} \mathrm{L} \mathrm{L}^{-1}$. The calibration equation was $\mathrm{Y}=0.001 \mathrm{C}+0.072$ with a correlation coefficient of 0.998 , where $\mathrm{Y}$ is the ratio of the area of MDA peak to the internal standard peak in the chromatogram, and $\mathrm{C}$ is the concentration of MDA in the sample solution $\left(\mu \mathrm{g} \mathrm{L}^{-1}\right)$. The limits of detection and quantification of the VADLLME method defined as $3 \mathrm{~S}_{\mathrm{b}} \mathrm{m}^{-1}$ and $10 \mathrm{~S}_{\mathrm{b}} \mathrm{m}^{-1}$ (where $\mathrm{S}_{\mathrm{b}}$ is the standard deviation of ten times extraction and measuring the blank and $\mathrm{m}$ is the slope of the calibration graph) were found to be 0.798 and $2.66 \mu \mathrm{g} \mathrm{L}^{-1}$, respectively. The relative standard deviation (RSD) for ten replicate measurements of 5 and $750 \mu \mathrm{g} \mathrm{L}^{-1}$ of MDA was found to be $7.65 \%$ and $5.48 \%$, respectively. An enrichment factor of 175 was obtained when analysis of a MDA standard solution with a concentration of $1.0 \mathrm{mg} \mathrm{L}^{-1}$ was performed by the proposed method and compared to the direct injection of $1.0 \mu \mathrm{L}$ of the same standard to GC [30]. The analytical figures of merit for the proposed method obtained under optimal conditions are summarized in Table 4.

Table 4. Analytical figures of merit for VADLLME extraction of MDA.

\begin{tabular}{|l|l|}
\hline Parameter & Analytical feature \\
\hline Equation of calibration curve & $\mathrm{S}=0.001 \mathrm{CMDA}+0.072$ \\
\hline Dynamic range $\left(\mu \mathrm{g} \mathrm{L}^{-1}\right)$ & $10-1150$ \\
\hline $\mathrm{R}^{2}$ (determination coefficient) & 0.998 \\
\hline Repeatability (RSD $\left.\%, \mathrm{n}=10,5 \mu \mathrm{g} \mathrm{L}^{-1}\right)$ & 7.65 \\
\hline Repeatability $\left(\mathrm{RSD} \%, \mathrm{n}=10,750 \mu \mathrm{g} \mathrm{L}^{-1}\right)$ & 5.48 \\
\hline Limit of detection $\left(\mu \mathrm{g} \mathrm{L}{ }^{-1}\right)$ & 0.798 \\
\hline Limit of Quantification $\left(\mu \mathrm{g} \mathrm{L}^{-1}\right)$ & 2.66 \\
\hline Enrichment factor (fold) & 175 \\
\hline
\end{tabular}

${ }^{*} \mathrm{RSD}$, relative standard deviation.

\section{Analysis of human blood plasma}

To evaluate the applicability of the VADLLME-GC method, it was applied to the analysis of blood plasma sample of humans without any pretreatment. In the first step, $250 \mu \mathrm{L}$ of blood plasma was transferred into $100 \mu \mathrm{L}$ of $6 \mathrm{M} \mathrm{NaOH}$, and then heated in a hot water bath at $60{ }^{\circ} \mathrm{C}$ for 30 minutes. After cooling to 2 ${ }^{\circ} \mathrm{C}, 500 \mu \mathrm{L}$ of $20 \% \mathrm{w} / \mathrm{v}$ trichloroacetic acid was added. The mixture was vortexed for $1 \mathrm{~min}$ and the sample was left for $10 \mathrm{~min}$ at ambient temperature for completion of the reaction. The mixture was then centrifuged at 10,000 rpm for 10 min at $4{ }^{\circ} \mathrm{C}$. The resulting deproteinized supernatant solution was transferred into a $6 \mathrm{~mL}$ vial and diluted to volume with ultrapure water and then analyzed [31], in which MDA was detected at the concentration of $284.7 \mu \mathrm{g} \mathrm{L}^{-1}$ ( $\mathrm{RSD}=6.0 \%, \mathrm{n}=3$ ). The GC chromatogram obtained from VADLLME for MDA extraction without sample spiking is depicted in Figure 4. For validation of this analysis, the most common method of MDA analysis, which is spectrophotometry [31, 32] was used. This gave the MDA concentration 297.3 $\mu \mathrm{g} \mathrm{L}{ }^{-1}$. As can be seen, the measured value is in good agreement with the standard method of MDA analysis at $95 \%$ confidence interval.

In order to investigate the validity of the proposed method for different concentrations, blood plasma samples were also spiked at three levels of 5, 25 and $50 \mu \mathrm{g} \mathrm{L}^{-1}$ with MDA. All the steps mentioned above were performed to remove proteins. Results are presented in Table 5. As can be seen, good recoveries between $95.8 \%$ to $106.0 \%$ were achieved which indicate that different levels of MDA can be measured successfully by using VADLLME-GC method. Relative standard deviation $(n=3)$ better than $7.15 \%$ was obtained.

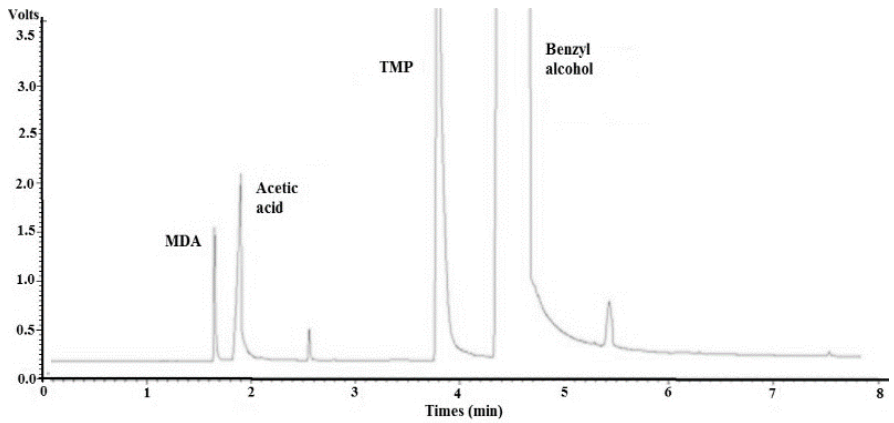

Figure 4. GC chromatogram obtained from VADLLME extraction. Extraction conditions: extraction solvent, benzyl alcohol; extraction solvent volume, 150 $\mu \mathrm{L}$; dispersive solvent, acetic acid; dispersive solvent volume, $450 \mu \mathrm{L}$; vortex time, $60 \mathrm{~s}$; centrifuge time, $4 \mathrm{~min}$; sample volume, $6 \mathrm{~mL} ; \mathrm{pH}, 3$; MDA = malondialdehyde; TMP = 1,1,3,3-tetramethoxypropane (internal standard).

Table 5. Analysis of MDA in a spiked plasma sample by the VADLLME extraction.

\begin{tabular}{|c|c|c|c|}
\hline $\begin{array}{c}\text { MDA added } \\
\left(\mu \mathrm{g} \mathrm{L}^{-1}\right)\end{array}$ & $\begin{array}{l}\text { MDA found } \\
\left(\mu \mathrm{g} \mathrm{L}^{-1}\right)\end{array}$ & Recovery (\%) & $\operatorname{RSD}(\%), n=3$ \\
\hline$\overline{5}$ & $\begin{array}{l}284.7 \\
290.0\end{array}$ & $\begin{array}{c}- \\
106.0\end{array}$ & $\begin{array}{l}6.05 \\
7.15\end{array}$ \\
\hline 25 & 309.1 & 97.6 & 5.87 \\
\hline 50 & 332.6 & 95.8 & 6.70 \\
\hline
\end{tabular}

Comparison of the suggested method with related techniques

Table 6 compares the characteristic data of the present method with those using gas chromatography for determination of MDA, reported in the literature recently. The limit of detection and enrichment factor obtained by the present method in most cases is in the same order of magnitude of the other methods, while it has the advantages such as a higher accuracy, wider linear dynamic range and faster analysis time. In addition, simplicity of operation, low cost and low sample volume are some other advantages of the proposed methods which can be used for preconcentration of malondialdehyde in human serum samples.

Table 6. Comparison of the proposed method with other reported methods involving GC detection for determination of MDA.

\begin{tabular}{|c|c|c|c|c|c|c|c|c|}
\hline Sample & Extraction Technique & $\begin{array}{l}\text { Detection } \\
\text { Technique }\end{array}$ & EF & $\underset{\left(\mu \mathrm{g} \mathrm{L}^{-1}\right)}{\text { LOD }}$ & $\begin{array}{c}\text { Linear Range } \\
\left(\mu \mathrm{g} \mathrm{L}^{-1}\right)\end{array}$ & $\begin{array}{l}\text { Repeatability } \\
\text { (RSD, \%) }\end{array}$ & $\begin{array}{c}\text { Estimated Analysis } \\
\text { Time (min) }\end{array}$ & Ref. \\
\hline Human Plasma & HS-SPME & GC/MS & NM & 0.4 & $5-100$ & $<8 \%$ & $\sim 50$ & [14] \\
\hline Complex Lipid Matrix & HS-SPME $^{*}$ & $\mathrm{GC}$ & NM & 0.742 & $\mathrm{NM}^{* * *}$ & NM & NM & [15] \\
\hline Human Plasma & SS-SDME $^{* *}$ & GC & 204.2 & 0.760 & $10-1000$ & 8.37 & $\leq 16$ & {$[30]$} \\
\hline Human Plasma & VADLLME & GC & 175 & 0.798 & $10-1150$ & 5.48 & $\leq 13$ & This work \\
\hline
\end{tabular}

${ }^{*}$ Headspace solid phase microextraction.

${ }^{* *}$ Salt saturated single-drop microextraction.

${ }^{* * *}$ Not mentioned. 


\section{CONCLUSION}

In the present study, a rapid and efficient analytical method based on vortexassisted dispersive liquid-liquid microextraction was studied and optimized for the determination of trace amounts of malondialdehyde in human serum plasma using one-variable-at-a-time and response surface methodology. For optimization of the malondialdehyde pre-concentration, seven factors in fivelevels were employed for design of experiments. The results showed that the proposed method exhibits good linearity, precision, enrichment factor and detection limit for the extraction of this analyte. This method is fast, simple, sensitive, and inexpensive and allows sample extraction and pre-concentration to be done in a single step. This technique is environmentally friendly, since only less than a mililiter of organic solvent is required for extraction. More than 170 fold pre-concentration makes this method of choice for trace analysis of MDA and potentially other similar compounds without the need for a derivatization step. The total analysis time is $13 \mathrm{~min}$.

\section{REFERENCES}

1. Z. Singh, I. P. Karthigesu, R. Kaur, Iran J. Public. Health 43, 7, (2014).

2. M. Rosenblat, R. Coleman, M. Aviram, Atherosclerosis 163, 17, (2002).

3. I. Delimaris, E. Faviou, G. Antonakos, E. Stathopoulou, A. Zachari, Clin. Biochem. 40, 1129, (2007).

4. A. M. Domijan, J. Ralić, S. Radić Brkanac, L. Rumora, T. Žanić-Grubišić, Biomed. Chromatogr. 29, 41, (2015).

5. K. -C. Hsu, P. -F. Hsu, Y. -C. Chen, H. -C. Lin, C. -C. Hung, P. -C. Chen, Y. -L. Huang, J. Chromatogr. B 1019, 112, (2016).

6. E. M. Gioti, Y. C. Fiamegos, D. C. Skalkos, C. D. Stalikas, J. Chromatogr. A 1152, 150, (2007).

7. D. Tsikas, S. Rothmann, J. Y. Schneider, M. -T. Suchy, A. Trettin, D. Modun, N. Stuke, N. Maassen, J. C. Frölich, J. Chromatogr. B 1019, 95, (2015).

8. B. Liu, Y. Qi, M. Li, Y. Gao, X. Chen, Z. -T. Wang, Chin. Sci. Bull. 12, 36, (2010).

9. D. W. Wilson, H. N. Metz, L. M. Graver, P. S. Rao, Clin. Chem. 43, 1982, (1997).

10. S. H. Hashemi, M. Kaykhaii, F. Tabehzar, J. Iran Chem. Soc. 13, 733, (2016)
11. H. Hashemi, M. Khajeh, M. Kaykhaii, Anal. Methods 5, 2778, (2013).

12. M. Khajeh, M. Kaykhaii, M. Mirmoghaddam, H. Hashemi, J. Environ. Anal. Chem. 89, 981, (2009).

13. H. Uslu, D. Datta, D. Santos, H. S. Bamufleh, C. Bayat, Chem. Engineer. J. 299, 342, (2016).

14. M. Kaykhaii, A. Khatibi, J. Iran Chem. Soc. 8, 374, (2011).

15. M. Kaykhaii, H. Yahyavi, M. Hashemi, M. R. Khoshroo, 408, 4907, (2016)

16. J. -L. Chen, Y. -J. Huang, C. -H. Pan, C. -W. Hu, M. -R. Chao, Free Radic. Biol. Med. 51, 1823, (2011).

17. H. -S. Shin, J. Chromatogr. B 877, 3707, (2009).

18. K. Fujioka, T. Shibamoto, J. Agric. Food Chem. 53, 4708, (2005).

19. R. Heydari, S. Zarabi, Anal. Methods 6, 8469, (2014).

20. J. Gañán, D. Pérez-Quintanilla, S. Morante-Zarcero, I. Sierra, J. Hazard. Mater. 260, 609, (2013).

21. A. Mehdinia, A. Ghassempour, H. Rafati, R. Heydari, Anal. Chem. Acta 587, 82, (2007).

22. M. Rezaee, Y. Assadi, M. -R. M. Hosseini, E. Aghaee, F. Ahmadi, S. Berijani, J. Chromatogr. A 1116, 1, (2006).

23. S. H. Hashemi, M. Kaykhaii, R. Dehvari, Current Chromatogr. 4, 1, (2017).

24. M. Nassiri, M. Kaykhaii, S. H. Hashemi, M. Sepahi, Iran. J. Chem. Chem. Eng. 37, 89, (2018).

25. M. Khajeh, M. Kaykhaii, S. H. Hashemi, M. Shakeri, J. Food Compos. Anal. $33,32,(2014)$

26. J. Vichapong, R. Burakham, S. Srijaranai, Talanta 117, 221, (2013).

27. E. Yiantzi, E. Psillakis, K. Tyrovola, N. Kalogerakis, Talanta 80, 2057 (2010).

28. V. Hosseinpour, M. Kazemeini, A. Mohammadrezaee, Appl. Catal. A 394, 166 (2011).

29. K. Yetilmezsoy, S. Demirel, R. J. Vanderbei, J. Hazard. Mater. 171, 551, (2009).

30. M. Mirmoghaddam, M. Kaykhaii, M. Hashemi, Anal. Methods 8, 2456 (2016)

31. J. Lovrić, M. Mesić, M. Macan, M. Koprivanac, M. Kelava, V. Bradamante, Periodicum biologorum 110, 63, (2008)

32. A. H. S. Muñoz, M. P. Puga, K. Wrobel, M. E. G. Sevilla, K. Wrobel, Microchimica Acta 148, 285 (2004) 